\title{
DYSPEPSIA MANAGEMENT
}

\section{Approaches to uninvestigated dyspepsia}

\section{R H Jones}

Uninvestigated dyspepsia refers to patients with new or recurrent dyspeptic symptoms in whom no investigations have previously been undertaken. These patients are much more likely to present in primary than in secondary care. It is particularly important to be able to offer effective symptom relief to support the explanation, reassurance, and advice provided to patients, and low dose or standard dose proton pump inhibitor therapy appears to offer the most effective approach to empirical therapy of this kind.

\begin{abstract}
SUMMARY
Uninvestigated dyspepsia refers to patients with new or recurrent dyspeptic symptoms in whom no investigations have previously been undertaken. These patients are much more likely to present in primary than in secondary care. The primary care physician has to employ strategies to ensure that patients with common symptoms representing serious disease are identified and dealt with expeditiously while applying a more measured approach to the majority of patients who are unlikely to have a serious cause for their symptoms. The management of dyspepsia in primary care is likely to embrace a number of approaches. The first of these is a non-drug approach, in which patients' ideas, beliefs, and fears about the cause of their symptoms and their likely implications are directly addressed, confronted, and corrected. A range of pharmaceutical interventions is available, with a therapeutic hierarchy beginning at simple antacids, then antacid-alginate mixtures, through to $\mathrm{H}_{2}$ receptor antagonists and prokinetic drugs, to the more effective proton pump inhibitors. Other components of the management strategy in primary care include tests for Helicobacter pylori infection, upper gastrointestinal endoscopy, and referral to a specialist. It is particularly important to be able to offer effective symptom relief to support the explanation, reassurance, and advice to patients, and low or standard dose proton pump inhibitor therapy appears to offer the most effective approach to empirical therapy of this kind.
\end{abstract}

Correspondence to: Professor R H Jones, Wolfson Professor of General Practice, Department of General Practice and Primary Care, Guy's, King's, and St Thomas' School of Medicine, 5 Lambeth Walk, London, SE 11 6SP UK; gp@umds.ac.uk

\section{INTRODUCTION}

Functional dyspepsia is not the same as uninvestigated dyspepsia. For a diagnosis of functional dyspepsia to be made, a number of investigations will have been performed and will have been found to be normal, notably upper gastrointestinal endoscopy, upper abdominal ultrasonography, and routine haematology and biochemistry screening blood tests. Uninvestigated dyspepsia, by contrast, refers to patients with either new or possibly recurrent dyspeptic symptoms in whom no investigations have previously been undertaken.

These patients are much more likely to present in primary than in secondary care. They will consult for a variety of reasons, and the primary care physician is faced with a wide range of management options to deal with them. In this paper, the range of management options available in primary care is outlined, data from five randomised controlled trials of antisecretory agents undertaken in primary care are reviewed, and the role of initial empirical acid suppressive therapy is discussed and defined. The place of $H$ pylori testing and eradication, and the timing of endoscopy in the management of newly presenting patients with dyspepsia are the subjects of accompanying papers in this supplement.

\section{DYSPEPSIA IN PRIMARY CARE}

The distinctive tasks of primary and secondary care physicians have been elegantly clarified by Marinker, who commented that "the role of the generalist is to marginalize danger, while that of the specialist is to marginalize uncertainty". ${ }^{1}$ The primary care physician has to employ diagnostic and management strategies which ensure that the minority of patients presenting with symptoms representing serious disease are identified and dealt with expeditiously while applying a more measured and conservative approach to the investigation and management of the majority of patients who are unlikely to have a serious organic or psychiatric cause for their presenting symptoms.

Other characteristics of the diagnostic and management processes employed by primary care physicians relate to the use of time as both a diagnostic and therapeutic tool and also to the considerable background information often held by primary care physicians about patients, their lives, and their families, not to mention their medical histories. Time can be used to clarify presentations that initially appear diffuse and vague, and can also be used, particularly when accompanied by a clear explanation and accurate prognostication, as a means of ensuring, by watchful waiting, that self limiting conditions resolve with the minimum need for intervention or resource utilisation.

\section{PRINCIPLES OF MANAGEMENT}

The primary care physician, faced with a patient with uninvestigated dyspepsia, will need to adhere to certain principles of management to ensure that care is delivered appropriately.

Firstly, management should be safe; physicians need to be attuned to the importance of alarm 
symptoms in dyspeptic patients, and exercise appropriate diagnostic suspicion for serious problems when alarm symptoms are present. Older patients presenting with new symptoms, for example, or those in whom general examination indicates the presence of systemic upset, may be regarded as at high risk of serious organic problems and merit swift referral or investigation. Patients in whom alarm symptoms are not present but in whom symptoms persist or relapse in the face of appropriate therapy also give cause for concern and may merit investigation or specialist referral.

Secondly, management needs to be patient centred. This is particularly important in dyspepsia. We know that the prevalence of dyspeptic symptoms in the general population is high, probably between $20 \%$ and $40 \%$ in the USA and the UK, but that only about $25 \%$ of these patients seek medical advice for their problems. ${ }^{23}$ Follow up studies indicate that although patients may move between the subgroups of dyspepsia, most non-consulters (that is, those who do not seek healthcare) remain non-consulters over time. ${ }^{4}$ We also know that the reasons for which patients seek healthcare for dyspepsia relate much less to the severity, pattern, or frequency of their symptoms than to the interpretations placed on them and the anxieties that these symptoms engender. In a formal comparison, it was shown that most of the variance between consulting and non-consulting dyspeptic patients was accounted for by patients' health beliefs and anxieties; in particular, fears of cancer and, especially in patients with reflux symptoms, heart disease led to patients consulting. ${ }^{5}$

Not only is it important to appreciate the patient's concerns when they consult for symptoms that to a physician may seem relatively trivial but it is also important to be attuned to a patient's desired treatment outcomes. For example, many therapeutic trials in dyspepsia define complete symptom relief at a given time point as the principal end point for analysis and efficacy. Given the frequency of dyspeptic symptoms, this may be an inappropriate goal for many patients, for whom reassurance, explanation, and symptom control (cf abolition) may be an entirely acceptable outcome.

Thirdly, management needs to be cost effective. The resources available for healthcare are shrinking worldwide; management, investigations, and drug therapy must all be delivered within a context of cost containment and cost effectiveness. This is particularly important in patients with dyspepsia due to the high cost of investigations and drugs used in treatment.

Fourthly, management must be part of a clinically appropriate pathway of care, possibly based on guidelines agreed between primary and secondary care, and certainly appropriate to the medical setting and the patient's presenting problems and clinical needs.

Finally, management should whenever possible be based on evidence of efficacy, utility and cost effectiveness of investigations, and interventions. Evidence based medicine has dominated much of our clinical thinking in recent years and while not always welcome, has focused our attention on the need to abandon practices that are not clinically effective and to absorb into our management strategies new interventions based on the evidence of well conducted clinical studies and secondary analyses.

\section{ASSESSMENT}

The primary care physician occupies a key gatekeeper role in many healthcare systems, and makes critical decisions about the need for patients to move into more sophisticated sectors of healthcare provision. This places considerable responsibility for accurate evaluation on the primary care physician, and in patients with dyspepsia this must be based on a full assessment of a number of factors. The duration, frequency, and severity of symptoms, often going back over a period of years, need to be clarified and documented. The symptom pattern and precipitating and relieving factors related to the symptoms (including the use of over the counter medication and other home remedies) should also be described. Valuable clues that, for example, may distinguish gastro-oesophageal reflux disease from ulcer-like dyspepsia can be gathered early in the consultation on the basis of simple questions. Asking the patient about the principal or most bothersome symptom may further clarify the likely source of the upper gastrointestinal symptoms. The importance of alarm symptoms is always emphasised although clinical trial evidence to support the widely made recommendations about urgent investigation and referral in patients with alarm symptoms is lacking. Patients over the age of 50 years presenting with new symptoms, those with pain or difficulty on swallowing, unusually early satiety, weight loss, anaemia, symptoms that recur after effective therapy, patients on non-steroidal anti-inflammatory drugs and, possibly, patients with a high level of anxiety about the cause of their symptoms may all justify relatively urgent investigation and/or referral.

The first consultation is the ideal opportunity to explore and clarify patients' health beliefs and anxieties. As discussed earlier, the interpretation placed by patients on their symptoms is a key factor in their decision to seek healthcare; if we overlook this, particularly in patients who appear to us to be complaining of relatively trivial symptoms, we are in danger of going down altogether inappropriate management paths. This consultation is also an important opportunity to consider the patient's family as well as social and psychological contexts. A history of psychological or psychiatric disorders is likely to be important, and a brief mental state examination, undertaken as part of the general interview, should alert the physician to the possibility of a primary psychological or psychiatric problem for which dyspeptic symptoms have become a somatic manifestation.

\section{MANAGEMENT OPTIONS}

The management of dyspepsia in primary care is likely to embrace a number of approaches. The first of these is a non-drug approach in which patients' ideas, beliefs, and fears about the cause of their symptoms and their likely implications are directly addressed, confronted, and where necessary corrected. The majority of patients presenting with dyspepsia in UK general practice harbour fears about cancer and heart disease; failure to get to grips with these anxieties early in the course of management is likely to cause problems later.

A range of pharmaceutical interventions is available with a therapeutic hierarchy beginning at simple antacids, moving on to antacid-alginate mixtures, through to $\mathrm{H}_{2}$ receptor antagonists and prokinetic drugs, to the more effective antisecretory agents the proton pump inhibitors. Drug regimens that eradicate $H$ pylori are also widely available, and other components of the management strategy in primary care include a range of tests for $H$ pylori infection, upper gastrointestinal endoscopy, and referral for a specialist opinion.

In practice, the primary care physician has four management options. The first of these is to send the patient for early endoscopy (prompt endoscopy), and there is some evidence that this may be a cost effective approach. ${ }^{6}$ However, when endoscopy is expensive, inaccessible, or associated with a long waiting time for patients, empirical therapy with an antisecretory drug may be employed. Few randomised controlled trials comparing prompt endoscopy with empirical therapy are available; Goulston et al in Australia compared these two approaches several years ago and concluded that they were comparable in terms of both cost and clinical outcomes. ${ }^{7}$ Bytzer et al in 1994 concluded that a prompt endoscopy approach was preferred by patients and was associated with 


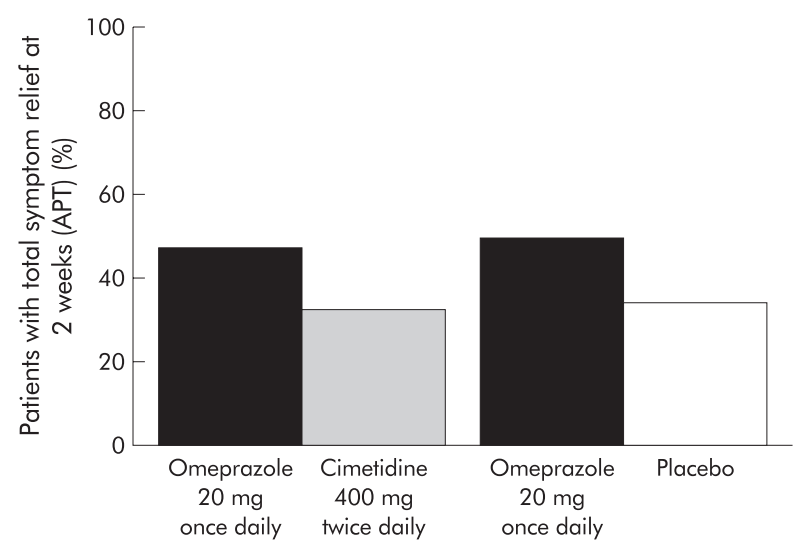

Figure 1 Omeprazole versus cimetidine and omeprazole versus placebo in uninvestigated dyspeptic patients in primary care. ${ }^{10} \mathrm{APT}$, all patients treated.

lower costs and comparable clinical outcomes than an empirical therapeutic approach based on $\mathrm{H}_{2}$ receptor antagonists. ${ }^{6}$

Two other strategies for management are available, both based on $H$ pylori testing. In the first of these, the so-called "test and investigate" strategy, patients presenting with uninvestigated dyspepsia are tested for $H$ pylori infection (preferably using a urea breath test but often using one of a variety of $H$ pylori serology tests), and those testing positive are selected for endoscopy. Patients who are $H$ pylori negative are regarded as not having peptic ulcer disease and, unless they have dominant reflux symptoms, are regarded as having functional dyspepsia. The fourth strategy, the "test and treat" strategy, involves the administration of $H$ pylori eradication therapy to all patients with uninvestigated dyspepsia (without alarm symptoms) who test positive for the bacterium. This approach acknowledges that there will be an element of over treatment but has the considerable advantage of greatly reducing the number of endoscopies required and therefore the costs associated with dyspepsia management. ${ }^{89}$ These management strategies are considered further in accompanying papers in this supplement.

\section{ANTISECRETORY THERAPY}

Studies investigating the role of antisecretory therapy in uninvestigated dyspepsia in primary care are few in number. These studies, inevitably, are beset by design and methodological problems, not least because without prior endoscopy it is impossible to characterise accurately patients in whom the trial is being conducted. This has sometimes made support for studies of this kind difficult to obtain and has also presented problems in publication. Recruitment in primary care may also be problematic, not least because primary care physicians see a wide range of patients, often with more troublesome problems, and sustaining a high rate of recruitment of dyspeptic patients into studies of this kind may be difficult. Finally, we need to consider the definition of "primary care" in other healthcare systems in which first contact care may be provided by, for example, specialists rather than general practitioners.

The first study to be considered was undertaken by Meineche-Schmidt and Krag in Denmark, and was published in $1997 .{ }^{10}$ In this study, patients with ulcer-like or reflux-like dyspeptic symptoms were randomised to treatment with omeprazole $20 \mathrm{mg}$ once daily or cimetidine $400 \mathrm{mg}$ twice daily if the patient had a verified medical history of peptic ulcer disease or reflux oesophagitis $(n=469)$, or to treatment with omeprazole $20 \mathrm{mg}$ once daily or placebo if no such history was present $(n=548)$. The end point of the study was total relief of symptoms after two weeks of therapy.

\begin{tabular}{|c|c|c|}
\hline & $\begin{array}{l}\text { Omeprazole } 10 \mathrm{mg} \\
\text { once daily (n (\%)) }\end{array}$ & $\begin{array}{l}\text { Antacid-alginate } 10 \mathrm{ml} \text { four } \\
\text { times daily }(\mathrm{n}(\%))\end{array}$ \\
\hline \multicolumn{3}{|c|}{ Duration of dyspepsia symptoms } \\
\hline$<1$ y & $61(18 \%)$ & $55(16 \%)$ \\
\hline $1-5 y$ & $89(27 \%)$ & $108(32 \%)$ \\
\hline$>5 y$ & $183(55 \%)$ & $174(52 \%)$ \\
\hline \multicolumn{3}{|c|}{ Frequency of dyspeptic symptoms in previous 7 days } \\
\hline$<1$ day & 0 & $1(<1 \%)$ \\
\hline $2-6$ days & $203(61 \%)$ & $202(60 \%)$ \\
\hline 7 days & $130(39 \%)$ & $134(40 \%)$ \\
\hline
\end{tabular}

The results of this study are summarised in fig l. In the omeprazole versus cimetidine arm of the study, there was a therapeutic gain of omeprazole of some $14 \%$, which was statistically significant $(\mathrm{p}=0.004)$, with a relatively low cimetidine response rate of $33 \%$. In the all patients treated analysis of the second arm of the study, omeprazole versus placebo, similar results were obtained, with $50 \%$ of the omeprazole treated patients being completely symptom free at two weeks compared with $35 \%$ of those on placebo. However, we do not know in this study, as in many other similar studies, how many patients who did not experience complete symptom relief were nonetheless content with therapy. This underlines the importance of designing studies in the community in which the end points relate to patients' desired outcomes as well as more traditional "medical" outcomes.

Some preliminary insights into the efficacy of proton pump inhibitors in the short term management of uninvestigated dyspepsia have come from two studies published by Jones and Baxter in $1997^{11}$ and by Jones and Crouch in $1999 .{ }^{12}$ In the first of these, the proton pump inhibitor lansoprazole $30 \mathrm{mg}$ once daily was compared with ranitidine $150 \mathrm{mg}$ twice daily in the treatment of acid related dyspepsia in general practice. This was a double blind, parallel group, randomised, multicentre study conducted in 32 centres in the UK; 213 patients were randomised to receive lansoprazole and 219 to receive ranitidine, both for four weeks. All patients had experienced symptoms of reflux-like or ulcer-like dyspepsia on at least four of the seven days prior to the study. Three quarters of these patients had suffered from dyspepsia in the past and about one third of the patients in each group had documented histories of acid related disorders, previously investigated by either radiology or endoscopy. After two weeks, 55\% of the lansoprazole treated patients and $33 \%$ of the ranitidine group were symptom free $(p=0.01)$, with corresponding four week values of $69 \%$ and $44 \%$, respectively.

In the second study, lansoprazole $15 \mathrm{mg}$ once daily was compared with omeprazole $10 \mathrm{mg}$ once daily, also in the treatment of uninvestigated dyspepsia in general practice in the UK. The same network of practitioners, members of the Primary Care Society for Gastroenterology, was used as the sampling frame. Overall, total symptom relief at two weeks was experienced by approximately $55 \%$ of the 609 patients participating in this study, with evidence of greater short term benefit in the lansoprazole treated patients.

Uninvestigated dyspepsia has been subjected to further formal investigation in two large, open, randomised, parallel group studies undertaken in primary care. In the OMEGA study, 674 dyspeptic patients with heartburn and/or epigastric pain as their predominant symptom who had no previous documented history of peptic ulcer disease were randomised to either omeprazole $10 \mathrm{mg}$ once daily or antacid-alginate (Gaviscon; Reckitt and Colman Products Ltd, Hull, UK) $10 \mathrm{ml}$ four times daily, for four weeks in an open label, parallel group design..$^{13}$ The primary efficacy variable was the percentage of patients with complete symptom relief at two weeks. The 


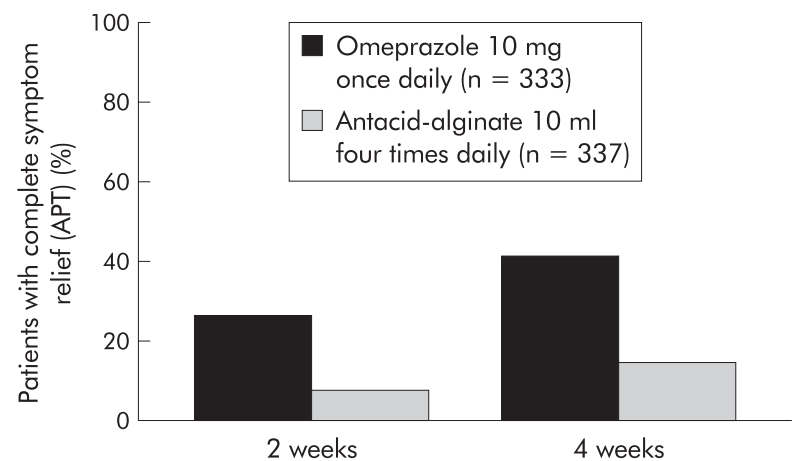

Figure 2 OMEGA study: results at two and four weeks. ${ }^{13}$ APT, all patients treated.

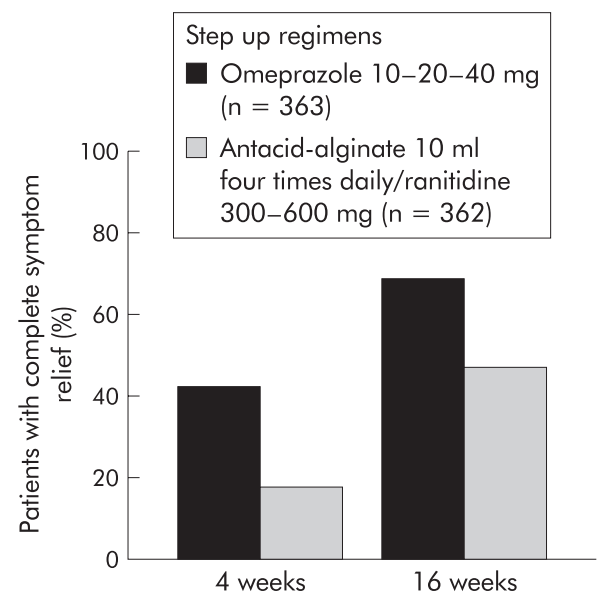

Figure 3 COMPETE study: results at four and 16 weeks. ${ }^{14}$

symptom profile of the patients included in the OMEGA study is shown in table 1. Over half of the patients had suffered dyspeptic symptoms for more than five years and most were experiencing symptoms on at least two days per week.

The results of this study are shown in fig 2. Among the 683 patients studied, $27 \%$ experienced complete symptom relief at two weeks in the omeprazole group compared with $8 \%$ in the antacid-alginate group (all patients treated analysis, $\mathrm{p}<0.0001$ ). At four weeks, the percentage of symptom free patients in the omeprazole group rose to $41 \%$ compared with only $15 \%$ in the antacid-alginate group (all patients treated analysis, $\mathrm{p}<0.0001$ ). These results were paralleled by patients' satisfaction with treatment in the study so that at four weeks $75 \%$ of the patients declared that they were satisfied (evaluated as "very convenient") with omeprazole therapy compared with $12 \%$ of the antacid-alginate group $(\mathrm{p}=0.0001)$.

In the second of these studies, the COMPETE study, 725 patients participated in a randomised, open, parallel group comparison lasting for 16 weeks. ${ }^{14}$ Patients were randomised to receive either omeprazole $10 \mathrm{mg}$ once daily, stepping up to $20 \mathrm{mg}$ and $40 \mathrm{mg}$ once daily as required $(\mathrm{n}=363)$, or an antacid-alginate/ranitidine treatment strategy, consisting of antacid-alginate $10 \mathrm{ml}$ four times daily, stepping up to ranitidine $150 \mathrm{mg}$ twice daily and $150 \mathrm{mg}$ four times daily as required $(n=362)$.

A greater proportion of patients randomised to the omeprazole strategy achieved the stringent outcome measure of complete symptom relief and a frequency of less than one day during the last seven days at 16 weeks $(61 \% v 40 \%$; $<<0.0001)$. The results at four and 16 weeks for complete symptom relief are shown in fig 3; at each time point there was a considerable therapeutic gain for the omeprazole strategy over the antacidalginate/ranitidine strategy. As in the OMEGA study, these therapeutic results were paralleled by an increased level of patient satisfaction with treatment in the omeprazole versus the antacid-alginate/ranitidine groups.

Finally, comparisons of quality of life in the OMEGA study significantly favoured the omeprazole group at both two and four weeks. ${ }^{13}$ Using the psychological general well being index and the gastrointestinal symptom rating scale, a significant difference was found between the two treatment arms. The effect of low dose omeprazole therapy on quality of life in uninvestigated dyspeptic patients is shown in fig 4 .

\section{CONCLUSION}

Patients presenting in primary care with dyspepsia often require symptom relief as a matter of some urgency. It is particularly important to be able to offer effective symptom relief to support the explanation, reassurance, and advice provided to patients, and low dose or standard dose proton pump inhibitor therapy appears to offer the most effective approach to empirical therapy of this kind. A therapeutic hierarchy is demonstrated, beginning at antacid-alginate combinations, through to $\mathrm{H}_{2}$ receptor antagonists to proton pump inhibitors.

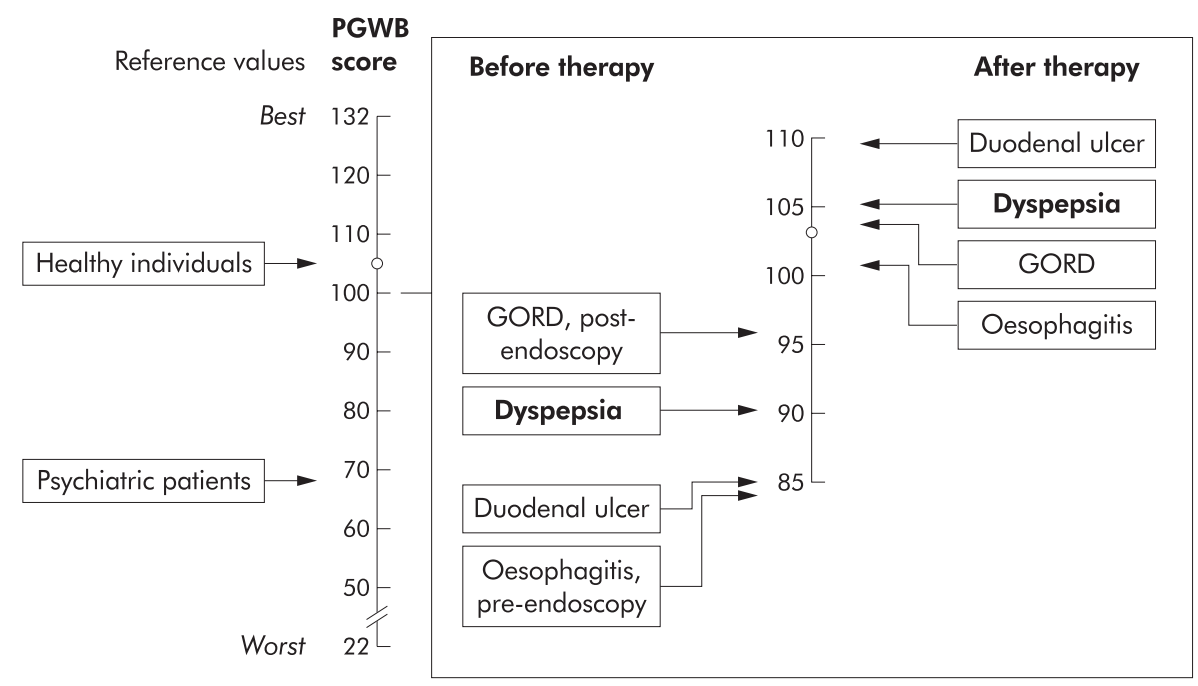

Figure 4 Quality of life before and after treatment of patients with uninvestigated dyspepsia managed in primary care. ${ }^{13}$ PGWB, psychological general well being index; GORD, gastro-oesophageal reflux disease. 
Higher doses of omeprazole may also be used for the "omeprazole test" to identify patients likely to have gastrooesophageal reflux disease, and this is also discussed by Fennerty in this supplement [see page iv63]. Empirical therapy must however be used judiciously and as part of an overall management plan in which symptom relief needs to be linked to a clear explanation for patients and a search for an accurate diagnosis that can act as a basis for definitive therapy or maintenance treatment.

Conflict of interest: This symposium was sponsored by AstraZeneca, makers of omeprazole. The author of this paper has recieved sponsorship for travel and an honorarium from AstraZeneca.

\section{REFERENCES}

1 Marinker M. Sense and sensibility in medicine. London: BM, 1997.

2 Jones RH, Lydeard SE, Hobbs FDR, et al. Dyspepsia in England and Scotland. Gut 1990;31:401-5.

3 Jones R. Self care and primary care of dyspepsia: a review. Fam Pract 1987;4:68-77.

4 Jones $\mathbf{R}$, Lydeard S. Dyspepsia in the community: a follow-up study. $\mathrm{Br} J$ Clin Pract 1992;46:95-7.

5 Lydeard S, Jones R. Factors affecting the decision to consult with dyspepsia: comparisons of consulters and non-consulters. J R Coll Gen Pract 1989;39:495-8.
6 Bytzer $\mathbf{P}$, Hansen JM, Schaffaliktsky de Muckadell OB. Empirical $\mathrm{H}_{2}$ blocker therapy or prompt endoscopy in the management of dyspepsia. Lancet 1994;343:811-16.

7 Goulston KJ, Dent OF, Mant A, et al. Use of $\mathrm{H}_{2}$ receptor antagonists in patients with dyspepsia and heartburn: a cost comparison. Med J Aust $1991 ; 155: 20-6$.

8 Patel P, Khulusi S, Mendall MA, et al. Prospective screening of dyspeptic patients by Helicobacter pylori serology. Lancet 1995;346:1315-18.

9 Jones R, Tait C, Sladen G, et al. A trial of a test and treat strategy for Helicobacter pylori-positive dyspeptic patients in general practice. Int $J$ Clin Pract 1999;53:413-16.

10 Meineche-Schmidt V, Krag E. Antisecretory therapy in 1017 patients with ulcerlike or refluxlike dyspepsia in general practice. Eur J Gen Pract 1997; 3:125-30.

11 Jones RH, Baxter G. Lansoprazole 30mg daily versus ranitidine 150mg bd in the treatment of acid-related dyspepsia in general practice. Aliment Pharmacol Ther 1997;11:541-6.

12 Jones R, Crouch SL. Low-dose lansoprazole provides greater relief of heartburn and epigastric pain than low-dose omeprazole in patients with acid-related dyspepsia. Aliment Pharmacol Ther 1999;13:413-19.

13 Goves J, Oldring JK, Kerr D, et al. First line treatment with omeprazole provides an effective and superior alternative strategy in the management of dyspepsia compared to antacid/alginate liquid: a multicentre study in general practice. Aliment Pharmacol Ther 1998;12:147-57.

14 Mason I, Millar LJ, Sheikh RR, et al. The management of acid-related dyspepsia in general practice: a comparison of an omeprazole versus an antacid-alginate/ranitidine management strategy. Aliment Pharmacol Ther 1998;12:263-71. 